Estudios Constitucionales, Año 13, No 1, 2015, pp. 163-202.

ISSN 07180195

Centro de Estudios Constitucionales de Chile Universidad de Talca

"Los estándares interpretativos de la Corte Interamericana de Derechos Humanos en materia de derechos políticos y la inconvencionalidad de la ley brasileña de inelegibilidades"

Luiz M. P. Bastos Jr. - Rodrigo Mioto dos Santos

\title{
LOS ESTÁNDARES INTERPRETATIVOS DE LA CORTE INTERAMERICANA DE DERECHOS HUMANOS EN MATERIA DE DERECHOS POLÍTICOS Y LA INCONVENCIONALIDAD DE LA LEY BRASILEÑA DE INELEGIBILIDADES ${ }^{* * *}$
}

\author{
The Interpretatives Standards of the Human Rights \\ InTER-AMERican COURT ON THE Political RightS AND the \\ INCONVENTIONALITY OF THE BRAZILLIAN LAW OF INELEGIBILITIES
}

\author{
LUIZ M. P. BASTOS JR. ${ }^{* * *}$ \\ Universidad do Vale do Itajaí \\ lmagno@univali.br \\ Rodrigo Mioto dos Santos*** \\ Universidad do Vale do Itajaí \\ rms@univali.br
}

RESUMEN: En el derecho brasileño, el derecho fundamental de concurrir a los pleitos electorales está sujeto al cumplimiento de un conjunto de condiciones de habilitación (condiciones de elegibilidad) y puede ser restringido ante la ocurrencia de causas de inelegibilidad, muchas de las cuales se presentan como sanciones de inhabilitación. El presente artículo tiene por objetivo confrontar la

\footnotetext{
* Trabajo recibido el 9 de septiembre de 2014 y aprobado el 6 de mayo de 2015.

** Esta investigación fue parcialmente financiada con recursos provenientes del CNPq (Proyecto 486144/2011-9, Edicto Universal 14/2011). Una versión ampliada de este artículo en idioma portugués se encuentra sometida a la apreciación del Consejo Editorial de la Revista Direito GV. Además, en este artículo, los autores incluyeron el análisis del Caso Yatama vs. Nicaragua, así como algunas consideraciones contextuales acerca del derecho electoral brasileño y de la práctica jurisprudencial de la Corte Constitucional brasileña (Supremo Tribunal Federal) en materia de la aplicación de los derechos internacionales de los derechos humanos.

*** Profesor de Derecho Constitucional y Derecho Procesal Constitucional en el curso de grado (Derecho y Relaciones Internacionales) y en el programa de posgrado en Ciencia Jurídica (Master y Doctorado). Abogado. Coordinador del Observatorio del Sistema Interamericano de Derechos Humanos de la Universidade do Vale do Itajaí.

**** Profesor de Derecho Penal y Procesal Penal y de Derechos Humanos en la Universidad do Vale do Itajaí. Coordinador del Observatorio del Sistema Interamericano de Derechos Humanos de la misma Universidad.
} 
Ley Brasileña de Inelegibilidades (Ley Complementaria $N^{\circ}$ 64/90) frente a la garantía prevista en la CADH (artículo 23). Se defiende, pues, que la casi totalidad de las hipótesis previstas en la norma local no sobrevivirían al análisis de compatibilidad con las garantías convencionales, según la jurisprudencia de la Corte Interamericana. Por último, se defiende que los jueces electorales, a despecho de la existencia de decisión vinculante emanada del Supremo Tribunal Federal (ADI 4578), deben negar vigencia a las reglas domésticas en orden de conferir eficacia ampliativa a los derechos politicos y a la propia democracia.

ABSTRACT: In the Brazilian law, the fundamental right to be elected can only be exercised if the citizen fulfills some legal requirements (eligibility conditions), and if he does not be framed in one the hypothesis defined by law as a ineligibility cause. In this article, I argue that almost all the hypothesis defined by the Brazilian Ineligibilities Act (LC n. 64/90) are not compatible with the guarantee ensured by the article 23 of American Convention on Human Rights, whereby all the citizens shall enjoy "the right and opportunity" (art. 23) to "be elected in genuine periodic elections" (art. 23,1.b), and the exercise of this right should be restrict "only on the basis of age, nationality, residence, language, education, civil and mental capacity, or sentencing by a competent court in criminal proceedings" (art. 23.2). Because of this, all the domestic judges are authorized to deny validity to the national statute, and apply directly the conventional guarantee, despite the fact that the Brazilian Supreme Court had uphold the Ineligibilities Act by a decision endowed with binding force for all the national judges.

Palabras ClaVE: 1. Control de Convencionalidad; 2. Derecho de ser elegido; 3. Ley de Inelegibilidades Brasileña.

KEY WORDS: 1. Control of conventionality; 2. Political right to be elected; 3. Brazilian Ineligibilities.

\section{INTRODUCCIÓN}

Entre las democracias constitucionales de América Latina, Brasil ha adoptado una postura de relativa indiferencia al Sistema Interamericano de Derechos Humanos. Esto se refleja tanto en la escasez de estudios doctrinarios sobre los estándares interpretativos de la Corte en casi todas las temáticas, como en la escasez de referencias en las decisiones de los tribunales brasileños (incluso la Corte Constitucional Brasileña, el Supremo Tribunal Federal) sobre las normas interamericanas.

Aquí y allá encontramos referencias a la jurisprudencia de la Corte, particularmente en situaciones en las que los posicionamientos de la Corte Interamericana coinciden con los posicionamientos adoptados por el Supremo Tribunal Federal, como es el caso en el que declaró que la Ley de Prensa Brasileña (Ley No 5.250/67) era incompatible con la Constitución Federal de $1988^{1}$, o la declaración de inconstitucionalidad del dispositivo que exigía diploma de curso superior en perio-

1 Supremo Tribunal Federal. Recurso Extraordinario n. 511.961, juzgado el 17.6.2009. 
dismo como condición para el ejercicio de la profesión de periodista (artículo 4º, inciso $5^{\circ}$, del decreto ley No 972/1969). ${ }^{2}$ En ambos casos el Supremo Tribunal Federal hizo referencia a la Opinión Consultiva No 7/86, dictada el 29.8.1986 por la Corte Interamericana, argumento que fue utilizado como refuerzo de las conclusiones a las que llegan los Ministros brasileños.

A pesar de eso, aún existe una larga ruta a caminar, como deja en evidencia el juicio del Supremo Tribunal Federal que declaró que es constitucional la Ley de Amnistía Nacional (Ley No 6.683/79)33, a despecho de la abundante jurisprudencia emanada de la Corte Interamericana que declaraba que no solamente eran inconvencionales las Leyes de Autoamnistía promulgadas en el continente latinoamericano, como declaraba que estas normas eran nulas de pleno derecho ${ }^{4}$. Esta situación acabó resultando en la condenación de Brasil en el Caso Gomes Lund y otros (Guerrilla del Araguaia) ${ }^{5}$, cuando la Corte determinó que la Ley brasileña no podría ser utilizada como obstáculo para la instauración de procesos de responsabilización de los militares involucrados en los crímenes de tortura y desaparición forzada durante la dictadura militar brasileña.

En relación a los derechos políticos, tema central de este artículo, igualmente no hay ninguna reflexión por parte de los autores brasileños sobre el impacto en la legislación doméstica y sobre el contenido y el alcance de la garantía convencional descrita en el artículo 23 de la Convención Americana de Derechos Humanos. Hasta el presente momento nada fue escrito sobre el asunto. Los manuales de derecho electoral y derecho procesal electoral brasileños permanecen en un silencio elocuente en cuanto a la Convención Americana de Derechos Humanos, pues en ninguno de ellos hay ni una única referencia a ese dispositivo, más aún en relación a las decisiones de la Corte Interamericana de Derechos Humanos ${ }^{6}$.

2 Supremo Tribunal Federal. Arguição de Descumprimento de Preceito Fundamental n. 130, juzgada el 30.4.2009.

3 Supremo Tribunal Federal. Arguição de Descumprimento de Preceito Fundamental n. 153, juzgada el 29.4.2010.

4 Corte IDH. Caso Almonacid Arrellano y otros vs. Chile. Excepciones Preliminares, Fondo, Reparaciones y Costas. Sentencia de 26 de septiembre de 2006. Serie C No 154; Corte IDH. Caso La Cantuta vs. Peru. Fondo, Reparaciones y Costas. Sentencia de 29 de noviembre de 2006. Serie C No 162; Corte IDH. Caso Barrios Altos vs. Perú. Fondo. Sentencia de 14 de marzo de 2001. Serie C No 75.

5 Corte IDH. Caso Gomes Lund y Otros (Guerrilha do Araguaia) vs. Brasil. Excepciones Preliminares, Fondo, Reparaciones y Costas. Sentencia de 24 de noviembre de 2010. Serie C No 219.

6 Coêlho, Marcus V.F. (2012); CÂndido, Joel José (2012); Costa, Adriano Soares (2013); Gomes, José Jairo (2013); ZiLIo, Rodrigo López (2012). 
En el derecho brasileño, el derecho fundamental de concurrir a los pleitos electorales está sujeto al cumplimiento de un conjunto de condiciones de habilitación (condiciones de elegibilidad) y puede ser restringido ante la ocurrencia de cualquiera de las causas de inelegibilidad, muchas de las cuales se presentan como sanciones de inhabilitación. De acuerdo con la legislación brasileña, estas causas de inelegibilidad consisten en efectos secundarios (o indirectos), definidos por la propia ley electoral, en relación a la práctica de conductas que, según la Ley de Inelegibilidades, revelarían falta de "moralidad para el ejercicio de mandato", o también que podrían configurar quiebra de "legitimidad de las elecciones". La promulgación de una Ley de Inelegibilidades está prevista directamente en el texto constitucional brasileño (artículo $14, \$ 9^{\circ}$ ).

Si la ley brasileña de inelegibilidades, en su redacción original de mayo de 1990 (Ley Complementaria No 64/90), ya era pródiga en la definición de hipótesis de inelegibilidad (en total eran ocho hipótesis), con la promulgación de la Ley Complementaria No 135/10 (Ley de la Ficha Limpia), que el 4 de junio de 2010 alteró la ley originaria, estas hipótesis se multiplicaron hasta llegar a 16 (dieciséis), además de lo cual hubo una serie de alteraciones en las reglas anteriores, volviéndolas mucho más gravosas.

La alteración legislativa fue consecuencia de un gran movimiento popular de combate a la corrupción electoral y fue desencadenada por iniciativa popular que reunió más de un millón y medio de firmas de electores pertenecientes a todos los Estados de la Federación brasileña. Esta indiscutible presión popular acabó resultando en una aprobación relámpago de esta norma, sin que la misma haya sufrido alteraciones legislativas sustantivas al texto presentado.

Cuando fue instado a manifestarse sobre la constitucionalidad de la referida norma, el Supremo Tribunal Federal juzgó que la totalidad del diploma legal era compatible con la Constitución Brasileña, sin haber hecho ninguna referencia al art. 23 de la Convención Americana de Derechos Humanos (Acción Directa de Inconstitucionalidad n. 4578, del 9.11.2011). La decisión proferida por la Corte Constitucional se reviste de eficacia vinculante y se impone obligatoriamente a todos los órganos judiciales brasileños.

Ocurre que, por ser signatario de la Convención Americana sobre Derechos Humanos, desde su promulgación interna decurrente del Decreto No 678, el 6 de noviembre de 1992, está en vigor la garantía expresa de que todos los ciudadanos deben gozar del derecho "de ser elegidos en elecciones periódicas auténticas" (art. 23, ítem 1, letra "b”). Estos derechos solo podrían ser restringidos con base en las causas definidas en el propio texto convencional, "exclu- 
sivamente por motivos de edad, nacionalidad, residencia, idioma, instrucción, capacidad civil o mental, o condenación, por juez competente, en proceso penal" (Artículo 23, ítem 2). El dispositivo convencional fue taxativo al restringir la libertad de conformación de los Estados Parte. Las restricciones a los derechos políticos enunciados en el art. 23 ítem 1 solo podrían ser promulgadas en estricta observancia de las hipótesis mencionadas en el texto (esto ante el término "exclusividad").

En este sentido, el presente artículo tiene por objetivo confrontar las hipótesis legales definidas en la Ley Complementaria No 64/90 frente a la garantía prevista en el art. 23.2 de la Convención Americana de Derechos Humanos. Se defiende, pues, que la totalidad de las hipótesis previstas por la Legislación Brasileña de Inelegibilidades (LC No 64, de 1990), con las alteraciones determinadas por la Ley de la Ficha Limpia (LC No 135, de 2010), no sobrevivirían al análisis de compatibilidad con las garantías convencionales, particularmente con el sentido que fue fijado en el Caso López Mendoza vs. Venezuela. ${ }^{7}$

La situación es todavía más dramática cuando se constata que en las últimas elecciones generales realizadas en $2012^{8}$, más de 1.631 candidatos tuvieron denegados sus pedidos de registro de candidatura por la Justicia Electoral brasileña. Gran parte de ellos, por haber sido encuadrado en alguna de las hipótesis de inelegibilidad definidas en la Ley de Inelegibilidades en cuestión.

El análisis tendrá como perspectiva la identificación de los estándares interpretativos fijados en los precedentes estudiados que permiten la comprensión del contenido y del alcance a ser atribuido a los dispositivos y obligaciones convencionales que se imponen a los Estados signatarios en materia de derechos políticos (en especial, el de ser elegido).

Esto es así porque el marco normativo supranacional no se restringe a la literalidad de la norma convencional, sino que debe ser analizado a la luz de su contexto normativo de significación, en otras palabras, en conjunto con el acervo jurisprudencial emanado de la Corte responsable por su adjudicación (como intérprete calificado de sus dispositivos) y por la interpretación dada por los órganos judiciales de los diferentes países igualmente signatarios de este mismo diploma

7 Corte IDH. Caso López Mendoza vs. Venezuela. Fondo, Reparaciones y Costas. Sentencia de 11 de septiembre de 2011. Serie C No 233.

8 En Brasil, las elecciones locales para los cargos de alcaldes y concejales están unificadas y ocurren concomitantemente en todos los municipios brasileños cada cuatro años. 
internacional. A fin de cuentas, la norma internacional debe ser interpretada de acuerdo con su contexto9.

Particularmente en relación a la regla en comento, existen tres importantes precedentes de la Corte Interamericana que enfrentaron específicamente el alcance de esa garantía convencional: el primero (Caso Yatama vs. Nicaragua ${ }^{10}$ ) en el que se discutió si las restricciones en la Ley Electoral introducida algunos meses antes de las elecciones generales de 2000, no se tradujeron en restricción arbitraria en el derecho de participación política de las comunidades indígenas y tradicionales en el proceso electoral; el segundo (Caso Castañeda Gutman vs. Estados Unidos Mexicanos ${ }^{11}$ ) en el que se discutió la posibilidad de asegurar la candidatura independiente a la Presidencia como consecuencia directa de la garantía convencional prevista en el art. 23.1.b; y el tercero (Caso López Mendoza vs. Venezuela ${ }^{12}$ ) en el que se discutió específicamente la aplicación de sanciones de inhabilitación en procesos administrativos (cómputo de sanción disciplinaria y regularidad en la ejecución presupuestaria), afirmando que esta hipótesis de suspensión de derechos políticos no estaría autorizada por el art. 23.2 de la Convención.

A fin de explorar este tema, el presente artículo está estructurado en los siguientes términos: en la primera parte se hará una breve incursión sobre las inelegibilidades definidas en la Ley Complementaria No 64/90; en la segunda parte, serán presentados los casos analizados por la Corte Interamericana de Derechos Humanos, a fin de que sea presentado el punto de vista de la Corte sobre el alcance de la garantía y sobre los límites a la actividad de conformación del legislador nacional; y en la tercera y última parte, se hará el análisis de (des) conformidad entre el diploma doméstico y los estándares interpretativos emanados de la Corte en relación a los artículos 23.1.b y 23.2 de la Convención Americana.

Con este esfuerzo se espera discutir las inelegibilidades en el derecho electoral brasileño desde el punto de vista de la garantía de los derechos humanos, con el objetivo de criticar la ausencia de reflexiones sobre las consideraciones del Sistema

9 Cfe. Lupi y Bastos JR. (2008), pp. 2490-2513.

10 Corte IDH. Caso Yatama vs. Nicaragua. Excepciones Preliminares, Fondo, Reparaciones y Costas. Sentencia de 23 de junio de 2005. Serie C No 127.

11 Corte IDH. Caso Castañeda Gutman vs. Estados Unidos Mexicanos. Excepciones Preliminares, Fondo, Reparaciones y Costas. Sentencia de 6 de agosto de 2008. Serie C No 184.

12 Corte IDH. Caso López Mendoza vs. Venezuela. Sentencia de 11 de setiembre de 2011, cit. nota 10. 
Interamericano de Derechos Humanos en la praxis doctrinal y jurisprudencial brasileña. A fin de cuentas, hay que tomar en serio los derechos políticos fundamentales, y el marco normativo interamericano ofrece parámetros sólidos en este sentido.

\section{DE LAS INELEGIBILIDADES LEGALES Y SU INTERPRETACIÓN por el Supremo Tribunal Federal}

Las inelegibilidades definidas en la Ley Complementaria No 64/90 encuentran su justificación en el próximo texto constitucional, in verbis:

" $\$ 9^{\circ}$ La ley complementaria establecerá otros casos de inelegibilidad y los plazos de su cesación, a fin de proteger la probidad administrativa, la moralidad para el ejercicio de mandato considerada la vida anterior del candidato, y la normalidad y legitimidad de las elecciones contra la influencia del poder económico o el abuso del ejercicio de función, cargo o empleo en la administración directa o indirecta”. ${ }^{13}$

A fin de dar concreción a este comando constitucional, fue editada la Ley de Inelegibilidades que, en su redacción originaria, listó en su artículo $1^{\circ}$ un conjunto de situaciones que, presentes, importarían en restricción temporaria al ius sufragii de los ciudadanos. Las restricciones fueron aquí agrupadas en cinco categorías, para fines de análisis, como se verá más adelante.

Ahora bien, la Ley de la Ficha Limpia operó un conjunto muy expresivo de alteraciones en relación a las inelegibilidades: las hipótesis fueron significativamente ampliadas (de ocho para dieciséis); los efectos decurrentes de decisiones judiciales pasaron a ser anticipados (o sea, la ley confirió efecto directo a las decisiones judiciales sancionatorias dictadas por órganos colegiados, sin que haya producido la cosa juzgada); los plazos de suspensión de los derechos políticos fueron ampliados (y uniformizados) en 8 (ocho) años; y por último, algunas hipótesis tuvieron alterada su redacción en algunos aspectos sustanciales.

El grupo de las hipótesis de inelegibilidades puede ser descrito así (las alteraciones fueron destacadas en itálico): (i) aquellos que no estén en el gozo de los derechos políticos (apartado "a”) (sin alteraciones); (ii) los agentes políticos, parlamentarios y jefes del Ejecutivo, que hayan tenido sus mandatos revocados por el Parlamento (inc. I, apartados "b" y "c") (plazo ampliado a 8 años) y que hayan renunciado a su mandato desde el ofrecimiento de petición que pudiese

13 Ley Complementaria No 64/90. 
resultar en la pena de casación (art. I, apartado "k") (hipótesis acrecida); (iii) aquellos agentes que hayan sido condenados en determinados procesos judiciales de índole electoral (inc. I, "d”, “j”, "n” y "p"), criminal (inc. I, "e", ampliación del rol de los crimenes) y civil (inc. I, "h", "l") (hipótesis adicionadas y plazos ampliados); (iv) aquellos que hayan sido sancionados en procesos administrativos (inc. I " $\mathrm{f}$ ", "g”, “i”, "m”, "o" y "q") (hipótesis adicionadas y plazos ampliados); (v) aquellos que no se hayan desincompatibilizado de determinados cargos públicos en el plazo fijado por la legislación (incs. II a VII) (sin alteraciones).

Frente a la naturaleza vinculante dirigida a todos los órganos del Poder Judicial y del Poder Ejecutivo (art. 102, $\$ 2^{\circ}$ de la Constitución Federal), por cuenta de la decisión dictada por el Supremo Tribunal Federal en 2011, los diferentes órganos judiciales se encuentran impedidos de suspender la aplicabilidad de cualesquiera dispositivos de la Ley Complementaria n. 135/2010, bajo el argumento de que ofenden a la Constitución. Se defiende más adelante que el juez nacional, a pesar de la decisión del Supremo Tribunal Federal, deberá dejar de aplicar esta norma justamente porque ella colisiona frontalmente con las garantías convencionales aseguradas en el art. 23.1.b y 23.2 de la Convención Americana ${ }^{14}$. Eso se verá a continuación.

\section{Del alCANCe del derecho de SeR VOtAdo PREVISTO EN la Convención AMERicana (arT. 23.1. B C/C ART. 23.2) y LAS OBLIGACIONES DE LOS ESTADOS PARTE}

En el ámbito del Sistema Interamericano de Derechos Humanos, el vínculo necesario entre democracia y derechos humanos está señalado en los principales pronunciamientos de la Corte Interamericana: los derechos políticos "propician el fortalecimiento de la democracia y el pluralismo político", en los términos del pronunciamiento de la Corte Interamericana de Derechos Humanos en los Casos Yatama vs. Nicaragua ${ }^{15}$ y Castañeda Gutman vs. Estados Unidos Mexicanos ${ }^{16}$.

14 Corte IDH. Caso Gomes Lund y otros (Guerrilha do Araguaia) vs. Brasil. Sentencia de 24 de noviembre de 2010, cit. nota 8, párr. 176 .

15 Corte IDH. Caso Yatama vs. Nicaragua. Sentencia de 23 de junio de 2005, cit. nota 13, párr. 192.

16 Corte IDH. Caso Castañeda Gutman vs. Estados Unidos Mexicanos. Sentencia de 6 de agosto de 2008, cit. nota 14, párr. 141. 
Estos derechos se encuentran expresamente contemplados en la Convención Americana de Derechos Humanos en los siguientes términos:

"Artículo 23. Derechos políticos

1. Todos los ciudadanos deben gozar de los siguientes derechos y oportunidades: (...)

b. de votar y ser elegidos en elecciones periódicas auténticas, realizadas por sufragio universal e igual y por voto secreto que garantice la libre expresión de la voluntad de los electores; y (...)

2. La ley puede regular el ejercicio de los derechos y oportunidades a las que se refiere el inciso anterior, exclusivamente por motivos de edad, nacionalidad, domicilio, idioma, instrucción, capacidad civil o mental, o condenación por juez competente en proceso penal". ${ }^{17}$

Al emprender un análisis sobre el alcance de los derechos políticos en la jurisprudencia de la Corte Interamericana y en los pronunciamientos de la Comisión Interamericana de Derechos Humanos, Alberto Dalla Via ${ }^{18}$ consigna que:

“(...) el adecuado ejercicio de los derechos políticos consagrados en el artículo 23 de la $\mathrm{CADH}$ se vincula con la vigencia de sus derechos y libertades entre los cuales se encuentran asociados el derecho a la libertad de expresión (artículo 13); a las garantías judiciales (artículo 8); el derecho de reunión (artículo 15), a la libertad de asociación (artículo 16), el derecho a la protección judicial (artículo 25); el derecho de libertad de investigación, opinión, expresión y difusión (IV); el derecho de asociación (XXII) y reunión (XXI); y el derecho de justicia (XVIII) de la DADH".

Así lo ha entendido la Corte Interamericana al sostener que: "los derechos políticos son derechos humanos de importancia fundamental dentro del sistema interamericano que se relacionan estrechamente con otros derechos consagrados en la Convención Americana, como la libertad de expresión, la libertad de reunión y la libertad de asociación y que, en conjunto, hacen posible el juego democrático" 19 .

En razón de ese vínculo indisociable entre democracia y derechos humanos, la máxima realización de la democracia representativa debe estar pautada por un

17 Convención Americana sobre Derechos Humanos (1969).

18 Dalla Via (2011), pp. 20-21.

19 Corte IDH. Caso Castañeda Gutman vs. Estados Unidos Mexicanos. Sentencia de 6 de agosto de 2008, cit. nota 14, párr. 140 . 
conjunto interpretativo consignado primariamente en el propio texto de la Convención. Fijadas estas premisas iniciales, conviene esbozar breves consideraciones sobre los precedentes de la Corte Interamericana a fin de que se puedan extraer de los mismos los estándares interpretativos que serán utilizados por los togados en la aplicación y realización del juicio de compatibilidad vertical entre las normas domésticas y las convencionales (res interpretata) ${ }^{20}$.

\subsection{Análisis del "Caso Yatama vs. Nicaragua". El vínculo esencial entre los derechos politicos y la democracia y la correlacion intrinseca entre el derecho de votar y de ser elegido}

El Caso Yatama vs. Nicaragua fue juzgado el 23 de junio de 2005 y gravitaba alrededor de la exclusión de los candidatos de YATAMA ${ }^{21}$ en las elecciones municipales de noviembre de 2000, en virtud de los cambios en la Ley Electoral (Ley No 331, del 24 de enero de 2000), que exigía que las candidaturas fuesen suscritas por partidos políticos, aboliendo la posibilidad de que "asociaciones de suscripción popular" participasen en las elecciones regionales.

El YATAMA es una organización regional, creada desde 1969 (bajo otra denominación), y con actuación en las dos regiones autónomas de la Costa Atlántica o Caribe (Región Autónoma del Atlántico Norte-RAAN-y la Región Autónoma del Atlántico Sur-RAAS). El régimen de autonomía de dichas regiones tiene base legal (ley No 28 de 2 de septiembre de 1987) y les reconoce a las comunidades de la Costa Atlántica la existencia del derecho al ejercicio efectivo "a participar en el diseño de las modalidades de aprovechamiento de los recursos naturales de la región” 22 . Estas regiones tienen población predominantemente mestiza, en que el 28\% de la población de la Costa Atlántica se identifica con alguna comunidad indígena.

El caso gravita sobre dos aspectos centrales, (i) la existencia de violaciones perpetradas por los órganos electorales (incluso el Consejo Supremo Electoral)

\footnotetext{
20 Cf. Ferrer Mac-gregor (2013), pp. 641-694.

21 La organización indígena YATAMA (Yapti Tasba Nanih Aslatakanka) es una organización "etnopolítica regional" que se formó con el propósito de "defender el derecho histórico de los pueblos indígenas y comunidades étnicas sobre sus territorios tradicionales y promover el autogobierno, impulsar el desarrollo económico, social y cultural de Yapti Tasba, forjando así la democracia comunitaria en el marco de la democracia, la paz y la unidad de estado/nación nicaragüense". Caso Yatama vs. Nicaragua, nota 13, párr. 124.11.

22 Corte IDH. Caso Yatama vs. Nicaragua. Sentencia de 23 de junio de 2005, cit. nota 13, párr. 124.3.
} 
al debido proceso legal (decisiones no debidamente fundamentadas y que no respetan la legislación interna respectiva) y a las garantías de protección judicial efectiva consagrada en el artículo 25.1 de la Convención; y (ii) la violación de los artículos 23 y 24 de la Convención en virtud de la promulgación de la Ley Electoral restrictiva de los derechos políticos de las comunidades indígenas y que no se compatibiliza con el dictamen del principio de la igualdad ante la ley (en su dimensión positiva).

La Corte reconoció la existencia de violación a los derechos de los candidatos del YATAMA en las elecciones municipales de 2000, pues los órganos electorales no habían respetado el debido proceso judicial (art. 8.1), no les aseguraron recursos judiciales efectivos y tempranos (art. 25.1) y las restricciones legales impuestas por la ley No 331 restringieron, indebidamente, el derecho a la participación de las comunidades indígenas socialmente organizadas (arts. 23.1 y 24).

Este caso es muy representativo porque fue el primer caso en el que la Corte enfrentó el alcance de los derechos políticos previstos en el artículo 23, no tanto por el hecho de que fueron apreciados en aquella oportunidad, muy relacionados con la definición de los derechos comunitarios de las poblaciones indígenas, sino sobre todo por las directrices que de él emanaron.

Estos estándares pueden ser sintetizados en los siguientes términos:

(i) los derechos políticos son esenciales en una sociedad democrática, pues propician "el fortalecimiento de la democracia y el pluralismo político"23, y como elementos integrantes de los derechos y libertades inherentes a la persona, juntamente con sus garantías y el Estado de Derecho "constituyen una tríada, en la que cada componente se define, completa y adquiere sentido en función de los otros"24;

(ii) las garantías del debido proceso, establecidas en el artículo 8 de la Convención, son aplicadas a "todos los órganos que ejerzan funciones de naturaleza materialmente jurisdiccional" $25 \mathrm{y}$, por supuesto, "las decisiones que emiten los órganos internos en materia electoral [ya que] pueden afectar el goce de los derechos políticos"26

23 Corte IDH. Caso Yatama vs. Nicaragua. Sentencia de 23 de junio de 2005, cit. nota 13, párr. 192.

24 Corte IDH. Caso Yatama vs. Nicaragua. Sentencia de 23 de junio de 2005, cit. nota 13, párr. 191.

25 Corte IDH. Caso Yatama vs. Nicaragua. Sentencia de 23 de junio de 2005, cit. nota 13, párr. 149. En este punto, la Corte hace referencia a sus juzgados (Caso Ivcher Bronstein, Sentencia de 6 de febrero de 2001. Serie C No 74, párr. 105; Caso del Tribunal Constitucional. Sentencia de 31 de enero de 2001. Serie C No 71, párr. 71; Caso Yatama vs. Nicaragua, Sentencia de 23 de junio de 2005. Serie C No 127, párr. 149).

26 Corte IDH. Caso Yatama vs. Nicaragua. Sentencia de 23 de junio de 2005, cit. nota 13, párr. 150. 
"deben estar debidamente fundamentadas, pues de lo contrario serían decisiones arbitrarias"27, "lo que implicaba señalar las normas en las que se fundamentaban los requisitos que estaba incumpliendo YATAMA, los hechos en que consistía el incumplimiento y las consecuencias de ello". 28

(iii) existe una estrecha relación entre el derecho a ser elegido y el derecho a votar para elegir representantes" 29 y, como tal, el derecho a ser elegido impone obligaciones al Estado, tanto de abstenerse de dictar restricciones legales indebidas y desrazonables (cuja violación se revela "particularmente grave"), como de cuidar que su ejercicio y "su aplicación sean acordes al principio de igualdad y no discriminación", adoptando todas "las medidas necesarias para garantizar su pleno ejercicio". 30

(iv) por último, que las restricciones a los derechos politicos, en cuanto derechos humanos fundamentales, deben ser interpretadas estrictamente, en consonancia con el art. 30.1 de la Convención, que estatuye la reserva de ley formal ${ }^{31}$ y la primacía de la norma más favorable a las víctimas.

Estos elementos fijarán las premisas conceptuales a partir de las cuales deben ser comprendidos los derechos políticos en el marco normativo del sistema interamericano de derechos humanos. Y, en cuanto tal, fueron concretizados (y reafirmados) en los dos casos siguientes en los que la Corte se pronunció sobre el contenido de los derechos políticos asegurados en el artículo 23 de la Convención, como se verá a continuación.

\subsection{Análisis del caso "Castañeda Gutman vs. Estados Unidos Mexicanos". La oportunidad de participación y limites a la actividad reglamentaria del Estado}

El Caso Castañeda Gutman vs. Estados Unidos Mexicanos fue juzgado el 6 de agosto de 2008 y gravita, en lo que respecta específicamente al objeto de este artículo, alrededor de dos aspectos fundamentales: la afirmación de que los Estados Parte tienen el deber de otorgar a los ciudadanos oportunidades efectivas para que los mismos ejerzan el derecho a participar en los asuntos

27 Corte IDH. Caso Yatama vs. Nicaragua. Sentencia de 23 de junio de 2005, cit. nota 13, párr. 152.

28 Corte IDH. Caso Yatama vs. Nicaragua. Sentencia de 23 de junio de 2005, cit. nota 13, párr. 153.

29 Corte IDH. Caso Yatama vs. Nicaragua. Sentencia de 23 de junio de 2005, cit. nota 13, párr. 197 y 226.

30 Corte IDH. Caso Yatama vs. Nicaragua. Sentencia de 23 de junio de 2005, cit. nota 13, párr. 201.

31 Cf. Corte IDH. La Expresión "Leyes” en el artículo 30 de la Convención Americana sobre Derechos Humanos. Opinión Consultiva OC-6/86 del 9 de mayo de 1986. Serie A No 6, párr. 34. 
políticos (art. 23.1.b) y sobre la limitación del poder de conformación de los Estados en lo referido a la reglamentación de los derechos políticos que, más allá de las restricciones explícitas definidas en el art. 23.2, deben estar sujetas al criterio de la proporcionalidad.

Los hechos sometidos a la apreciación de la Corte se referían al pedido de registro de candidatura individual e independiente a la Presidencia de la República, formulado por el Sr. Castañeda Gutman al órgano administrativo responsable por los registros (Consejo General del Instituto Federal Electoral). El pedido fue negado con el argumento de que solamente los partidos políticos nacionales gozan de la prerrogativa de solicitar el registro de candidaturas a mandatos electivos. Contra esa decisión, el Sr. Castañeda Gutman ingresó, sin éxito, con recurso de amparo a la Corte Regional Federal y recurso de casación a la Corte Suprema Mexicana (en esta última, con pedido de medida cautelar). Los órganos judiciales no reconocieron el pedido formulado por el Sr. Castañeda Gutman, pues entendieron que no poseía legitimidad activa para impugnar decisiones del órgano administrativo federal (legitimidad confiada solamente a los partidos políticos).

Al proponer la demanda, la Comisión postuló el reconocimiento de una doble violación a los derechos políticos de la víctima, el derecho a un recurso judicial efectivo (art. 25 de la Convención) y el derecho concreto a ver registrada su candidatura independiente (art. 23.1.b de la Convención), ya que la condición de afiliación previa a partido político no representaba una de las excepciones previstas por el art. 23.2 de la Convención. En razón de los objetivos de este artículo, el análisis del caso se limitará al segundo aspecto.

Ahora bien, en lo que respecta al alcance de los derechos políticos definidos en el art. 23.1 de la Convención, la Corte Interamericana fijó algunos importantes balizamientos. La Corte fija su atención sobre la peculiaridad de la obligación de los Estados que aseguren a los ciudadanos amplia oportunidad de participación en la vida política. Se extraen las siguientes directrices interpretativas transmitidas en este precedente:

"145. El artículo 23 contiene diversas normas que se refieren a los derechos de la persona como ciudadano, esto es, como titular del proceso de toma de decisiones en los asuntos públicos, como elector a través del voto o como servidor público, es decir, a ser elegido popularmente o mediante designación o nombramiento para ocupar un cargo público. Además de poseer la particularidad de tratarse de derechos reconocidos a los ciudadanos, a diferencia de casi todos los demás derechos previstos en la Convención que se reconocen a toda persona, el artículo 23 de la Convención 
no solo establece que sus titulares deben gozar de derechos, sino que agrega el término "oportunidades". Esto último implica la obligación de garantizar con medidas positivas que toda persona que formalmente sea titular de derechos políticos tenga la oportunidad real para ejercerlos. Como ya lo señalara este Tribunal anteriormente, es indispensable que el Estado genere las condiciones y mecanismos óptimos para que los derechos políticos puedan ser ejercidos de forma efectiva, respetando el principio de igualdad y no discriminación.

(...)

148. Por su parte, la participación política mediante el ejercicio del derecho a ser elegido supone que los ciudadanos puedan postularse como candidatos en condiciones de igualdad y que puedan ocupar los cargos públicos sujetos a elección si logran obtener la cantidad de votos necesarios para ello.

149. El derecho y la oportunidad de votar y de ser elegido consagrados por el artículo 23.1.b de la Convención Americana se ejerce regularmente en elecciones periódicas, auténticas, realizadas por sufragio universal e igual y por voto secreto que garantice la libre expresión de la voluntad de los electores. Más allá de estas características del proceso electoral (elecciones periódicas y auténticas) y de los principios del sufragio (universal, igual, secreto, que refleje la libre expresión de la voluntad popular), la Convención Americana no establece una modalidad específica o un sistema electoral particular mediante el cual los derechos a votar y ser elegido deben ser ejercidos (...). La Convención se limita a establecer determinados estándares dentro de los cuales los Estados legítimamente pueden y deben regular los derechos políticos, siempre y cuando dicha reglamentación cumpla con los requisitos de legalidad, esté dirigida a cumplir con una finalidad legítima, sea necesaria y proporcional; esto es, sea razonable de acuerdo a los principios de la democracia representativa". 32

Al reiterar la esencialidad de los derechos políticos, la Corte reconoció que el Estado Parte goza de una relativa libertad de conformación para definir los modelos electorales (ingenierías institucionales) a ser adoptados, de modo que:

“157. (...) la ley necesariamente tiene que establecer regulaciones que van más allá de aquellas que se relacionan con ciertos límites del Estado para restringir esos derechos, establecidos en el artículo 23.2 de la Convención. Los Estados deben organizar los sistemas electorales y establecer un complejo número de condiciones y formalidades para que sea posible el ejercicio del derecho a votar y ser votado. (...)

32 Corte IDH. Caso Castañeda Gutman vs. Estados Unidos Mexicanos. Sentencia de 6 de agosto de 2008, cit. nota 14, párr. 145, 148 y 149. 
161. Como se desprende de lo anterior, la Corte estima que no es posible aplicar al sistema electoral que se establezca en un Estado solamente las limitaciones del párrafo 2 del artículo 23 de la Convención Americana". 33

Con todo, prosigue la Corte, esta relativa libertad de conformación no elimina la posibilidad de control por parte de la Corte Interamericana de Derechos Humanos,

"161. (...) Sin embargo, las medidas que los Estados adoptan con el fin de garantizar el ejercicio de los derechos convencionales no están excluidas de la competencia de la Corte Interamericana cuando se alega una violación de los derechos humanos previstos en la Convención. Consecuentemente, la Corte debe examinar si uno de esos aspectos vinculados a la organización y reglamentación del proceso electoral y de los derechos políticos, la exclusividad de nominación de candidatos a cargos federales por parte de los partidos políticos, implica una restricción indebida a los derechos humanos consagrados en la Convención". ${ }^{34}$

Por lo tanto, tras reafirmar su competencia para conocer sobre la alegada violación a la Convención, la Corte pasa a emprender un riguroso control de convencionalidad de la ley mejicana aplicando los siguientes test: la observancia de la reserva legal estricta (legalidad de la medida restrictiva, párrs. 176-179) y la comprobación de la no existencia de exceso con base en los postulados del principio de la proporcionalidad (finalidad, párrs. 180-184; necesidad, párrs. 185-202; proporcionalidad en sentido estricto, párrs. 203-205).

Al final, la Corte reconoció que el Estado "no violó, en perjuicio del señor Jorge Castañeda Gutman, el derecho político a ser elegido reconocido en el artículo 23.1.b de la Convención Americana sobre Derechos Humanos, (...)” (párr. 251.3).

A pesar de que la Corte retiró la violación al art. 23.2 de la Convención del caso en análisis, fijó dos importantes directrices interpretativas que gozan de especial proyección para los propósitos de este artículo:

(i) los derechos políticos son esenciales para la democracia e imponen una serie de exigencias de protección, considerando el deber de asegurarles a los ciudadanos la

33 Corte IDH. Caso Castañeda Gutman vs. Estados Unidos Mexicanos. Sentencia de 6 de agosto de 2008, cit. nota 14, párr. 145 y 161.

34 Corte IDH. Caso Castañeda Gutman vs. Estados Unidos Mexicanos. Sentencia de 6 de agosto de 2008, cit. nota 14, párr. 161. 
oportunidad de participar efectivamente en la formación de la voluntad política del Estado (consolidación de las premisas conceptuales fijadas en el Caso Yatama vs. Nicaragua);

(ii) en el ejercicio del deber de reglamentación de los sistemas electorales, el Estado puede fijar condiciones no previstas en el art. 23.2 para hacer viable el ejercicio al derecho de votar y ser votado, pero la actividad de conformación del Estado está sujeta al control de compatibilidad a ser emprendido por las instituciones del Sistema Interamericano (sujeción a la regla de proporcionalidad).

\subsection{Análisis del caso "López Mendoza vs. Venezuela". La sanción de inhabilitación (Inelegibilidad) solamente puede ser proferida por órgano judicial, en proceso penal}

El Caso "López Mendoza vs. Venezuela" fue juzgado el 1 de setiembre de 2011 y discute exactamente los límites impuestos a los Estados en lo que respecta a las restricciones a los derechos políticos pasivos (derecho de ser elegido). La cuestión de derecho enfrentada por la Corte es la siguiente: si se faculta a los Estados a definir nuevas causas de restricciones no previstas en el art. 23.2 de la Convención Americana.

Analicemos los hechos sometidos a la apreciación de la Corte Interamericana. El Sr. Leopoldo López Mendoza fue elegido en 2000 (y reelegido en 2004) alcalde del Municipio de Chacao, unidad integrante del Distrito Metropolitano de Caracas. Al final del segundo mandato, pretendía postularse a la Alcaldía Mayor de Caracas (órgano político administrativo que congrega la región metropolitana de Caracas); sin embargo, le fue impedido presentarse como candidato a causa de la imposición de dos sanciones de inhabilitación (sanciones de inelegibilidad) decretadas por el Controlador General de la República, la primera, resultado del proceso que investigó la existencia de conflicto de intereses cuando, antes de ser intendente, trabajaba en la empresa Petróleos de Venezuela S.A. (PDVSA) y como voluntario en una organización no gubernamental que recibió subvenciones sociales de la estatal venezolana; y la segunda, decurrente de la aplicación de multa por haber usado recursos presupuestarios en desacuerdo con la finalidad legal, en el ejercicio del mandato de Intendente Municipal.

En razón del primer procedimiento, el órgano administrativo le aplicó una sanción pecuniaria (multa) equivalente a US\$ 647,50 y posteriormente, siguiendo el rito procedimental local, fue editada una Resolución de inhabilitación para el ejercicio de funciones públicas por 3 años. En razón del segundo procedimiento, el órgano administrativo le aplicó multa (equivalente a 
US\$ 4.239,58) y luego, por entender que la conducta era grave y que sería un caso de reincidencia, editó una Resolución de inhabilitación para el ejercicio de funciones públicas por el período de 6 años. Ambas decisiones fueron confirmadas por la Sala Constitucional del Tribunal Supremo de Justicia, que rechazó los recursos de nulidad requeridos para revocar estas decisiones. En virtud de estas sanciones, el Sr. Leonardo López Mendoza no pudo inscribirse para la postulación del cargo de Intendente del Distrito Metropolitano de Caracas ante la Junta Electoral del referido distrito.

Al proponer la demanda, la Comisión postuló que fuese reconocida la violación al derecho de ser elegido (ofensa al art. 23.1.b y 23.2 de la Convención); la existencia de ofensa a las garantías judiciales en los procedimientos administrativos realizados; y además la existencia del deber de adoptar disposiciones de derecho interno para salvaguardar tales garantías convencionales. Este trabajo enfocará más detenidamente el primer aspecto.

La cuestión fue delimitada por la Corte en los siguientes términos:

"100. El punto central del presente caso radica en las sanciones de inhabilitación impuestas al señor López Mendoza por decisión de un órgano administrativo en aplicación del artículo 105 de la LOCGRSNCF, que le impidieron registrar su candidatura para cargos de elección popular. Luego de reseñar los alegatos de las partes, la Corte determinará si dichas sanciones y sus efectos sobre la presunta víctima son o no compatibles con la Convención Americana". ${ }^{35}$

Entre las innumerables razones presentadas por el Estado contra la alegada incompatibilidad, se destacan los siguientes argumentos:

(i) el art. 105 de la ley nacional fue promulgado en estricta observancia de la constitución venezolana, razón por la que una eventual antinomia del mismo con el art. 23.2 no resulta en automática prevalencia de ese art. en relación a la Constitución de Venezuela;

(ii) la sanción de inhabilitación impuesta por el Controlador General no es de naturaleza política porque no implica en una suspensión de todos los derechos políticos, sino solamente lo inhabilita para ejercer determinadas funciones públicas por determinado período;

(iii) un sinnúmero de otros países sancionaron normas semejantes en el contexto de la lucha contra la corrupción;

35 Corte IDH. Caso López Mendoza vs. Venezuela. Sentencia de 11 de septiembre de 2011, cit. nota 10, párr. 100. 
(iv) la sanción de inhabilitación que impone el Controlador tiene como objetivo la lucha contra la corrupción y la protección del erario público, el cual corresponde a un interés público imperativo.

En relación al primer y tercer argumentos, la Corte se pronunció:

"104. (...) No corresponde, en cambio, que la Corte se pronuncie sobre la interpretación del derecho interno venezolano y, en particular, sobre la compatibilidad o incompatibilidad del artículo 105 de la LOCGRSNCF con la Constitución de Venezuela. Asimismo, la Corte considera que para decidir el presente caso no es necesario realizar un pronunciamiento respecto a los alegatos de derecho comparado presentados por el Estado.

105. En relación a la situación analizada, la Corte entendió que se trata de hipótesis de aplicación directa del art. 23 de la Convención, 'porque se trata de sanciones que impusieron una clara restricción a uno de los derechos políticos reconocidos por el párrafo 1 de dicho artículo, sin ajustarse a los requisitos aplicables de conformidad con el párrafo 2 del mismo'”. 36

El razonamiento emprendido por la Corte fue lineal y eliminó de manera categórica las dos oposiciones hechas por el Estado, in verbis:

"106. El artículo 23.1 de la Convención establece que todos los ciudadanos deben gozar de los siguientes derechos y oportunidades, los cuales deben ser garantizados por el Estado en condiciones de igualdad: i) a la participación en la dirección de los asuntos públicos, directamente o por representantes libremente elegidos; ii) a votar y a ser elegido en elecciones periódicas auténticas, realizadas por sufragio universal e igual y por voto secreto que garantice la libre expresión de los electores, y iii) a acceder a las funciones públicas de su país.

107. El artículo 23.2 de la Convención determina cuáles son las causales que permiten restringir los derechos reconocidos en el artículo 23.1, así como, en su caso, los requisitos que deben cumplirse para que proceda tal restricción. En el presente caso, que se refiere a una restricción impuesta por vía de sanción, debería tratarse de una 'condena, por juez competente, en proceso penal'. Ninguno de esos requisitos se ha cumplido, pues el órgano que impuso dichas sanciones no era un 'juez competente', no hubo 'condena' y las sanciones no se aplicaron como resultado de un 'proceso penal', en el que tendrían que haberse respetado las garantías judiciales consagradas en el artículo 8 de la Convención Americana.

36 Corte IDH. Caso López Mendoza vs. Venezuela. Sentencia de 11 de setiembre de 2011, cit. nota 10, párrs. 104 y 105. 
108. La Corte estima pertinente reiterar que 'el ejercicio efectivo de los derechos políticos constituye un fin en sí mismo y, a la vez, un medio fundamental que las sociedades democráticas tienen para garantizar los demás derechos humanos previstos en la Convención y que sus titulares, es decir, los ciudadanos, no solo deben gozar de derechos, sino también de oportunidades'. Este último término implica la obligación de garantizar con medidas positivas que toda persona que formalmente sea titular de derechos políticos tenga la oportunidad real para ejercerlos. En el presente caso, si bien el señor López Mendoza ha podido ejercer otros derechos políticos (supra párr. 94), está plenamente probado que se le ha privado del sufragio pasivo, es decir, del derecho a ser elegido.

109. En virtud de lo que antecede, la Corte determina que el Estado violó los artículos 23.1.b y 23.2 en relación con el artículo 1.1 de la Convención Americana, en perjuicio del señor Leopoldo López Mendoza”. ${ }^{37}$

Así de sencillo. La opinión mayoritaria de la Corte ni siquiera consideró los argumentos del Estado en relación a la existencia de un esfuerzo de combate a la corrupción. La Corte trató de reconocer que el dispositivo convencional impone una obligación clara de que los Estados solo podrían restringir los derechos políticos fundamentales (el de ser elegido, en este caso) como resultado de la práctica de un comportamiento considerado ilícito (inelegibilidad conminada), solamente si este proveimiento judicial ostentase los tres elementos previstos en la parte final del art. 23.2: haber sido emitido por juez competente, haber existido una condena (con tránsito en juicio) y haber sido proferido en un proceso penal.

A su vez, emprendiendo auténtico control judicial de convencionalidad, la Corte analizó la compatibilidad del derecho interno (art. 105 de la Ley Nacional) frente a la Convención, en los siguientes términos:

206. En consecuencia, al no cumplir con el requisito de previsibilidad y, además, teniendo en cuenta lo señalado en el sentido que el artículo 105 de la LOCGRSNCF permite la restricción del derecho a ser elegido por una autoridad que no es juez penal (supra párrs. 107 y 108), la Corte concluye que en el presente caso se vulneraron los artículos 8.1, 23.1.b y 23.2, en relación con los artículos 1.1 y 2 de la Convención Americana. ${ }^{38}$

37 Corte IDH. Caso López Mendoza vs. Venezuela. Sentencia de 11 de septiembre de 2011, cit. nota 10, párrs. 106-109.

38 Corte IDH. Caso López Mendoza vs. Venezuela. Sentencia de 11 de septiembre de 2011, cit. nota 10, párr. 206. 
En relación al punto específico, sobre la interpretación a ser atribuida al art. 23.2 y sobre la posibilidad de que la misma pudiese ser flexibilizada por las jurisdicciones de otros Estados, hubo un embate vigoroso entre los Jueces Diego García-Sayán y Eduardo Vio Grossi, lo que se trasluce en los votos concurrentes presentados por ambos, añadidos a la opinión mayoritaria de la Corte.

El Juez Diego García-Sayán se levantó contra la interpretación literal prestada por la mayoría al art. 23.2 de la Convención Americana. El juez propuso una interpretación comprensiva al art. 23.3, admitiendo la posibilidad de que el Estado impusiese otras restricciones, siempre por la vía judicial (es digno de nota), mediante decisiones provenientes de otras instancias de responsabilización (civil, electoral, administrativa, p. ej.).

A su vez, el Juez Eduardo Vio Grossi fue contundente en afirmar que el dispositivo convencional

“(...) resulta claro, sencillo y categórico, particularmente en lo que en autos interesa, a saber, que 'el ejercicio de los derechos y oportunidades a que se refiere' el numeral 1 del mismo, especialmente el concerniente al derecho de 'ser elegido (...)', puede ser reglamentado 'exclusivamente' por, entre otras causales, 'condena, por juez competente, en proceso penal'”. 39

Acto seguido, el Juez Eduardo Vio Grossi emprendió un esfuerzo en desconstruir las razones presentadas por su colega, aduciendo estar equivocada la referencia hecha a las técnicas de interpretación de derecho internacional a la expresión "exclusivamente" (del art. 23.2). A fin de cuentas, "la Sentencia ha procedido fijando el sentido y alcance de este último según su única alternativa de aplicación posible". ${ }^{40}$

Vale la pena registrar, por ser oportuno, el entendimiento fijado por Nogueira Alcalá, que actuó en el caso como perito. El mismo retira el argumento de que la Ley Nacional es inconvencional per se, pero acusa como inadecuado el pronunciamiento hecho por los órganos administrativo y judicial venezolanos. Afirma el constitucionalista chileno, con bastante propiedad, que la sanción administrativa accesoria de inhabilitación al ejercicio de cargos públicos por tiempo determinado,

39 Voto Concurrente del Juez Eduardo Vio Grossi en el Caso López Mendoza vs. Venezuela. Sentencia de 11 de septiembre de 2011.

40 Voto Concurrente del Juez Eduardo Vio Grossi en el Caso López Mendoza vs. Venezuela. Sentencia de 11 de septiembre de 2011. 
“(...) debería aplicarse solo a los cargos que tienen su origen en un acto administrativo de nombramiento por alguno de los órganos del Estado, pero no debería aplicarse ni podría constitucionalmente aplicarse para los funcionarios que fueren electos mediante sufragio. En esta última hipótesis, es el pueblo quien elige, en ejercicio de la soberanía popular, de acuerdo al artículo $5^{\circ}$ de la Constitución, no pudiendo un órgano administrativo contralor, conforme a la Constitución, limitarle al pueblo el ejercicio de su poder soberano". ${ }^{41}$

De todo lo expuesto se puede concluir que, en consonancia con el precedente analizado, la Corte Interamericana de Derechos Humanos entiende que:

(i) el derecho público de ser elegido (previsto en el art. 23.1.b de la Convención) es de índole fundamental y solo puede ser restringido en estricta observancia a las condicionantes definidas en el art. 23.2 de la Convención;

(ii) tratándose de suspensión de derechos políticos decurrentes de la aplicación de una sanción, para que la misma sea válida se hace imprescindible que haya sido proferida en virtud de una condena penal.

\subsection{Naturaleza jurídica de la sentencia interamericana. Eficacia erga omnes de los pronunciamientos de la Corte (res interpretata)}

La Corte considera las normas internas -actos administrativos, leyes, constitución, decisiones judiciales- como "meros hechos", expresiones de voluntad de los Estados, y procede al cotejo de estos hechos con la Convención ${ }^{42}$ buscando proteger la eficacia del objeto y fin del instrumento internacional ${ }^{43}$.

Al contrario, ante eventual incompatibilidad, la Corte declara la responsabilidad internacional del Estado por incumplimiento de la Convención y lo condena a adecuar el ordenamiento interno a la Convención ${ }^{44}$. Se trata, por lo tanto, de un examen de adecuación de una conducta del Estado con una prescripción internacional establecida ${ }^{45}$. En ese contexto son irrelevantes las justificativas in-

41 Nogueira Alcalá (2011a), pp. 361-362.

42 Cfr. Ramos (2005).

43 Cfr. Londoño Lázaro (2010), pp. 761-814.

44 Rey Cantor (2009).

45 Cfr. Londoño Lázaro (2010), pp. 761-814. 
ternas -aunque basadas en las propias Constituciones- sobre la existencia de un esfuerzo nacional de combate a la corrupción, o incluso la observancia de otros principios de interés público a justificar las restricciones legales.

Es verdad, como advierte Eduardo Ferrer Mac-Gregor ${ }^{46}$, que la eficacia vinculante (res judicata) solo se opera en relación al Estado Parte accionado por la Corte (en este caso, el Estado venezolano y nicaragüense), de modo que una corte nacional no puede "invalidar una decisión de una corte internacional y denegar la existencia de una violación al derecho internacional ya declarada a nivel internacional en un caso concreto".

Esto no significa vaciar los efectos de la decisión en relación a los demás países signatarios. Muy por el contrario, Eduardo Ferrer Mac Gregor defiende que la sentencia interamericana adquiere aún la eficacia "de manera objetiva e indirecta hacia todos los Estados Parte en la Convención Americana”, ya que:

“33. (...) se produce una eficacia erga omnes hacia todos los Estados Parte de la Convención, en la medida en que todas las autoridades nacionales quedan vinculadas a la efectividad convencional y, consecuentemente, al criterio interpretativo establecido por la Corte IDH, en tanto estándar mínimo de efectividad de la norma convencional, derivada de la obligación de los Estados de respeto, garantía y adecuación (normativa e interpretativa) que establecen los artículos $1^{\circ}$ y $2^{\circ}$ de la Convención Americana; y de ahí la lógica de que la sentencia sea notificada no solo 'a las partes en el caso' sino también 'transmitido a los Estados partes en la Convención’ en términos del artículo 69 del Pacto de San José.

El fundamento resulta, pues, de un compromiso compartido de otorgar efectividad regional a esos patrones reconocidos como mínimos aceptables. En el caso de que una interpretación nacional no se ajuste a este patrón mínimo, 'existe un incumplimiento de la obligación de 'adecuación' previsto en el artículo $2^{\circ}$ del Pacto de San José, es decir, al existir una inadecuada actuación interna con la Convención; $(\ldots))^{\prime \prime} .47$

En ese contexto, no les es dado a los Estados la facultad de excusarse de cumplir tales requisitos mínimos. Se extrae de la buena fe contractual que los Estados deben conferir aplicabilidad al dispositivo que sea más protector de la garantía de los derechos humanos, tampoco importando si son disposiciones de derecho interno o estándares interpretativos fijados por la Corte.

46 Ferrer Mac-gregor (2013), p. 665.

47 Ferrer Mac-gregor (2013), p. 666. 
En ambos precedentes analizados, ante el reconocimiento del derecho a la reparación económica por el daño experimentado por la víctima, la Corte determinó a los Estados que realizasen, en un plazo razonable, la adecuación de sus ordenamientos jurídicos nacionales a la obligación convencional que se consideró violada. De esta forma, la Corte determinó que fuesen removidos los óbices legislativos y/o que fuese adecuada la norma procesal doméstica a fin de que las directrices fijadas fuesen debidamente incorporadas a la legislación nacional.

El análisis de conformación entre el sistema brasileño de inelegibilidades (a la luz de la interpretación divulgada por el Supremo Tribunal Federal) y los estándares mínimos de protección del derecho político de ser elegido (ejercicio del derecho de sufragio pasivo) es lo que será objeto de apreciación específica en la próxima sección.

\section{El CONTROL DE CONVENCIONALIDAD Y LAS POSIBLIDADES DE ADECUACIÓN} DEL ORDENAMIENTO BRASILEÑO A LOS TÉRMINOS DE LA CONVENCIÓN

\subsection{El sistema legal de inelegibilidades y el análisis de compatibilidad con la Convención Americana de Derechos Humanos}

Para empezar, se vuelve importante reiterar los cuatro estándares interpretativos emanados de los dos últimos fallos analizados:

(i) los derechos políticos son esenciales a la democracia e imponen una serie de exigencias de protección, teniendo en cuenta el deber de asegurar a los ciudadanos amplia oportunidad de participar efectivamente en la formación de la voluntad política del Estado (Caso Castañeda Gutman vs. Estados Unidos Mexicanos);

(ii) en el ejercicio del deber de reglamentación de los sistemas electorales, el Estado puede fijar condiciones no previstas en el art. 23.2, a fin de permitir el ejercicio concreto del derecho de votar y ser votado (en el sentido de ejercicio de condiciones de habilitación); sin embargo, esta actividad no es libre y se sujeta al control de prohibición de exceso del principio de la proporcionalidad (Caso Castañeda Gutman vs. Estados Unidos Mexicanos);

(iii) el derecho de ser elegido (23.1.b) es derecho público subjetivo y solo puede ser restringido en estricta observancia a las causas definidas en el art. 23.2 (Caso López Mendoza vs. Venezuela);

(iv) tratándose de suspensión de derechos políticos ante la aplicación de una sanción, es imprescindible que esta reprensión advenga de juez competente, esté revestida de definitividad y haya sido proferida en proceso penal (Caso López Mendoza vs. Venezuela). 
La mera enunciación de estas premisas ya es per se reveladora. Las inelegibilidades precisan ser tratadas desde una perspectiva muy distinta de aquella que, hasta el momento, viene dominando los tribunales brasileños. A diferencia del discurso de matiz moralizante y excluyente que rige entre nosotros, la lógica que preside la materia en el ámbito del sistema interamericano es la de que los Estados deben ampliar al máximo los legitimados para lanzarse a los pleitos electorales (garantía de amplia oportunidad de participación en "pleitos periódicos y auténticos").

Por lo tanto, no son adecuadas las interpretaciones que sustraen el carácter de garantía fundamental a los derechos políticos pasivos (el derecho de ser elegido). El derecho a lanzarse como candidato en las elecciones es tan fundamental como el derecho de votar. Son dos facetas indisociables del jus sufraggi y que gozan de idéntica dignidad. "El ejercicio de los derechos a ser elegido y a votar, íntimamente ligados entre sí, es la expresión de las dimensiones individual y social de la participación política”. ${ }^{48}$

No hay que confrontar el derecho de ser votado al derecho a la democracia como bienes en contraposición, como consignaron, lamentablemente, los jueces del Supremo Tribunal Federal en la ADI No 4578.

De esta manera, la restricción del derecho público subjetivo de un candidato no afecta solamente su patrimonio jurídico, sino que alcanza a toda la colectividad, que ve reducida su libertad de elección democrática, y "su violación es muy grave” ${ }^{49}$. Se trata pues de una garantía institucional que trasciende (y excede) al ámbito de protección de los individuos que son afectados por la restricción del ejercicio de un derecho fundamental suyo (tiene, pues, una dimensión objetiva). Se trata de una perspectiva muy diferente de aquella que fue suscrita en la decisión del Supremo Tribunal Federal.

Asimismo, hay que llamar la atención sobre la (falta de) legitimidad del uso emprendido por el Supremo Tribunal Federal en lo que se refiere a la protección de la moralidad administrativa y a la defensa de las instituciones democráticas contra el abuso de derecho (extraídos del art. 14, $\$ 9^{\circ}$ de la CF). Los bienes contrapuestos en el juicio de proporcionalidad aplicado por la Corte brasileña adoptan parámetros (y puntos de partida) muy diferenciados de aquellos emprendidos por la Corte Interamericana. No es posible oponer el derecho

48 Cfr. Corte IDH. Caso Yatama vs. Nicaragua. Sentencia de 23 de junio de 2005, cit. nota 13, párr. 197.

49 Cfr. Corte IDH. Caso Yatama vs. Nicaragua. Sentencia de 23 de junio de 2005, cit. nota 13, párr. 197. 
político fundamental de ser elegido a la democracia, como quiere el STF, pues su promoción al máximo está íntimamente conectada al propio ejercicio de la democracia.

Lo que se revela sintomático en la jurisprudencia de la Corte Interamericana, es que el argumento de combate a la corrupción, de compatibilidad con el texto constitucional nacional y las necesidades imperiosas de salvaguarda del interés público, ni siquiera deben ser considerados cuando se está delante de ofensa directa a la garantía convencional fundamental. Estas hipótesis deben ser interpretadas en estricta consonancia a los condicionantes previstos en la propia Convención.

En otras palabras, tratándose de ley que restringe el derecho de ser elegido, no hay otra alternativa hermenéutica para la Corte que no sea la estricta observancia de las reglas consignadas en el art. 23.2, tomando en cuenta la máxima interpretativa del artículo 29. a de la Convención. Como consignó la Corte ${ }^{50}$,

204. De acuerdo al artículo 29.a) de la Convención no se puede limitar el alcance pleno de los derechos políticos de manera que su reglamentación o las decisiones que se adopten en aplicación de esta se conviertan en un impedimento para que las personas participen efectivamente en la conducción del Estado o se torne ilusoria dicha participación, privando a tales derechos de su contenido esencial.

De esta manera, cuando se pretende hacer el análisis de conformación entre la legislación brasileña sobre inelegibilidades, se hace imprescindible que las reglas brasileñas sean confrontadas con las causas definidas en este dispositivo convencional. Así, en la primera sección de este artículo se listaron grupos de causas de inelegibilidades. Estos grupos serán reproducidos a continuación, a medida que sean analizados en este artículo.

Para hacer el análisis de compatibilidad se hace necesario emprender un primer esfuerzo de diferenciación entre aquellas inelegibilidades resultantes de la decisión soberana del Estado, de relativa libertad de conformación del sistema electoral nacional, y el régimen de las inelegibilidades que serían resultantes de conminaciones fijadas por el Estado ante comportamientos considerados como incompatibles con la posibilidad del ejercicio del derecho político de ser elegido. $\mathrm{Y}$, acto seguido, se impone hacer un análisis sobre el cumplimiento (o no) de los

50 Cfr. Corte IDH. Caso Yatama vs. Nicaragua. Sentencia de 23 de junio de 2005, cit. nota 13, párr. 203. 
requisitos fijados por el art. 23.2 en relación a estas últimas hipótesis de inelegibilidades conminadas.

Pues bien, el primer grupo de inelegibilidades -aquellas que no gozan del derecho político pasivo tout court (inc. I, "a" ${ }^{51}$ ) - se refiere a las llamadas inelegibilidades innatas, es decir, resultantes de aquellas hipótesis en las que los ciudadanos no poseen los requisitos definidos por la legislación para ser reconocidos como titulares de derechos políticos pasivos (los no alistables) y, además, aquel grupo de ciudadanos que, a la par de ostentar el status de derecho político activo, frente al no cumplimiento de una condición mínima (ser alfabetizado), no le es conferido el derecho político pasivo (de ser elegido).

En relación al primer elemento (el alistamiento), un adecuado análisis de compatibilidad del orden brasileño al sistema internacional exigiría que se hiciese un análisis pormenorizado de las condiciones de alistamiento y, además, de las condiciones de elegibilidad definidas por la legislación. Ese análisis sería importante para que las hipótesis definidas en la legislación sean compatibles con las restricciones autorizadas por la Convención ("edad, nacionalidad, residencia, idioma, instrucción, capacidad civil o mental”). Y más adelante, habiendo sido identificada condición legal que no guarde relación directa con estas hipótesis, en los términos de lo que fue fijado en el Caso Castañeda Gutman vs. Estados Unidos Mexicanos, cabría hacer un esmerado escrutinio sobre la norma nacional a fin de comprobar si la restricción impuesta pasa por el test de legalidad y de proporcionalidad $^{52}$. Ese análisis excede los límites de este trabajo.

En relación al segundo elemento (la condición de analfabeto), esta restricción encuentra expresa previsión en el dispositivo convencional como causa para justificar límite al ejercicio de los derechos políticos previstos en el art. 23.1.b. El texto convencional expresamente consigna la "instrucción" como hipótesis para autorizar la edición de norma restrictiva de derechos. Por esta razón la norma pasaría por el test de convencionalidad.

Para que sea realizado el análisis de compatibilidad en relación a los demás grupos, resulta importante hacer un rápido análisis sobre la naturaleza de las inelegibilidades allí definidas. Esto es así porque, siendo consideradas como inelegibilidades conminadas (derivadas de sanciones), las mismas se sujetan al escrutinio estricto fijado en la parte final del art. 23.2 de la Convención.

51 Art. $1^{\circ}$. Son inelegibles: I - para cualquier cargo: a) los no alistables y los analfabetos.

52 Cfe. Nogueira Alcalá (2011b), pp. 119-156. 
Cuando se lanzó la propuesta de alteración legislativa que resultó en la LC No 135/2010 (Ley de la Ficha Limpia), el primer esfuerzo de desconstrucción emprendido se refería a la tentativa de dilucidar la naturaleza de la sanción de estas hipótesis de inelegibilidad, a fin de tratarla como condición objetiva de elegibilidad. Este esfuerzo resultaría de un

(...) relevante cambio de paradigmas en el derecho electoral patrio, asegurando la plena efectividad de lo dispuesto en el $\$ 9^{\circ}$ del art. 1 de la Constitución Federal e instituyendo importantes conquistas para el saneamiento de las costumbres políticas en el país, protegiendo la moralidad y la probidad administrativa en el ejercicio de mandatos, considerando la vida anterior del candidato. 53

En sentido diametralmente opuesto, diversos autores reiteraron la naturaleza sancionatoria de esta especie de inelegibilidad, pues ella resultaría de la violación de un bien jurídico protegido. En ese sentido, tales restricciones no se materializarían delante de un

(...) mero impedimento al ejercicio del jus honorum, se configura el encuadramiento en la tipología subsuntiva en una pena, en que incluso alejándose los ciudadanos del hecho jurídico descrito en la ley, aun así estará inelegible por el lapso temporal determinado en la reprimenda. ${ }^{54}$

Como fue dicho anteriormente, la cuestión no dejó de ser enfrentada por el Supremo Tribunal Federal. Muy por el contrario, la condición sine qua non para que aquella Corte reconociese la integral constitucionalidad del diploma consistía justamente en el expreso apartamiento de la noción de sanción de inelegibilidad, a fin de reconceptuarla como "causa de inelegibilidad", ante su condición objetiva de poder ser evaluada en ocasión del pedido de registro de candidatura. Sin la definición de esa premisa, sería difícil sustentar la constitucionalidad del diploma en lo que se refiere a las alegadas violaciones a la presunción de inocencia y a la irretroactividad de la ley (decurrente de la ampliación del tiempo de impedimento y de la inclusión de nuevas hipótesis).

En cierto sentido, la cuestión fue enfrentada por la Corte Interamericana en el Caso López Mendoza vs. Venezuela, cuando retiró el argumento de la Corte de

53 Côelho (2012), p. 55. (Traducción libre).

54 Agra (2012), p. 22. (Traducción libre). 
que la sanción aplicada no se revestía de naturaleza política, porque el mismo continuaba en el ejercicio de los demás derechos políticos. Este argumento igualmente fue utilizado en la decisión del Supremo Tribunal Federal, aunque la Corte Interamericana asentó que este elemento no era suficiente para descaracterizar la naturaleza sancionatoria de la norma reglamentadora.

La restricción del derecho político (aunque adscrita al derecho político pasivo) configura, para los efectos de la incidencia del art. 23.2, en restricción de naturaleza sancionatoria, lo que para la Corte solo puede ser considerado como compatible con la Convención Americana, en el caso de haber sido resultado de procedimiento definido en la parte final del mencionado dispositivo.

Es inarredable, pues, el carácter sancionatorio definido por las hipótesis de inelegibilidad previstas en los apartados "b" a "q", de la Ley brasileña de inelegibilidades. De este modo, se deben aplicar los estándares interpretativos extraídos directamente de la literalidad del texto convencional: “(iv) es imprescindible que esta reprensión advenga de juez competente, se revista de definitividad y haya sido proferida en proceso penal" (Caso López Mendoza vs. Venezuela).

Sin ni siquiera analizar detenidamente otros criterios para la comprobación de compatibilidad de las hipótesis legales brasileñas en relación a la Convención, la evidencia de las hipótesis que fueron agrupadas en el segundo grupo (agentes políticos inhabilitados o que hayan renunciado, hipótesis: apartados "b" 55 , "c"56 y " $k$ "57) y en el cuarto grupo (efectos indirectos de sanciones administrativas,

55 b) Los miembros del Congreso Nacional, de las Asambleas Legislativas, de la Cámara Legislativa y de las Cámaras Municipales, que hayan perdido los respectivos mandatos por infringir lo dispuesto en los incisos I y II del art. 55 de la Constitución Federal, los dispositivos equivalentes sobre pérdida de mandato de las Constituciones Estatales y Leyes Orgánicas de los Municipios y del Distrito Federal, para las elecciones que se realicen durante el período remanente del mandato para el cual fueron elegidos y en los ochos años subsiguientes al término de la legislatura.

56 c) El Gobernador y el Vicegobernador de Estado y del Distrito Federal y el Intendente y el Vice intendente que pierdan sus cargos electivos por infringir el dispositivo de la Constitución Estatal, de la Ley Orgánica del Distrito Federal o de la Ley Orgánica del Municipio, para las elecciones que se realicen durante el período remanente y en los 8 (ocho) años subsiguientes al término del mandato para el cual hayan sido elegidos.

57 k) El Presidente de la República, el Gobernador de Estado y del Distrito Federal, el Intendente, los miembros del Congreso Nacional, de las Asambleas Legislativas, de la Cámara Legislativa, de las Cámaras Municipales, que renuncien a sus mandatos desde el ofrecimiento de representación o petición capaz de autorizar la abertura de proceso por infringir el dispositivo de la Constitución Federal, de la Constitución Estatal, de la Ley Orgánica del Distrito Federal o de la Ley Orgánica del Municipio, para las elecciones que 
hipótesis: apartados "f"58, "g"59, "i" 60 , "m"61, "o" 62 y "q"63), no cumplen el primer requisito, a saber, haber sido la sanción de inelegibilidad resultante de la imposición de un juez competente. En cualquier contexto en el que se tomen en serio los derechos políticos fundamentales, no se puede consentir con la posibilidad de que las sanciones impuestas por autoridades administrativas (inclusive corporaciones) puedan tener tan grave efecto secundario: la expulsión de la vida pública de ciudadanos por inadmisibles ocho años.

En estas hipótesis, la mera confrontación ya permite que se excluya, de entrada, la posibilidad de reconocer como convencionales estas disposiciones normativas y, por consiguiente, admitir como compatibles con el régimen de protecciones de la Convención alejamientos determinados con base en esas premisas.

Dicho esto, conviene analizar el tercer grupo de inelegibilidades listadas como resultantes de decisión judicial. En este universo tenemos un conjunto de hipótesis que, presentes, atraen como consecuencia la inelegibilidad de aquel que fue sancionado en el ámbito de los procedimientos judiciales en cuestión.

se realicen durante el período remanente del mandato para el cual fueron elegidos y en los 8 (ocho) años subsiguientes al término de la legislatura.

58 f) Los que sean declarados indignos de la oficialía, o incompatibles con ella, por el plazo de 8 (ocho) años.

59 g) Los que tengan sus cuentas relativas al ejercicio de cargos o funciones públicas rechazadas por irregularidad insanable que configure acto doloso de improbidad administrativa, y por decisión no recurrible del órgano competente, salvo si esta hubiese sido suspendida o anulada por el Poder Judicial, para las elecciones que se realicen en los 8 (ocho) años siguientes, contados a partir de la fecha de la decisión, aplicándose lo dispuesto en el inciso II del art. 71 de la Constitución Federal, a todos los ordenadores de dispendio, sin exclusión de mandatarios que hayan actuado en esa condición.

60 i) Los que, en establecimientos de crédito, financiamiento o seguro, hayan sido o estén siendo objeto de proceso de liquidación judicial o extrajudicial, hayan ejercido, en los 12 (doce) meses anteriores a la respectiva decretación, cargo o función de dirección, administración o representación, mientras no sean exonerados de cualquier responsabilidad.

$61 \mathrm{~m}$ ) Los que sean excluidos del ejercicio de la profesión, por decisión sancionatoria del órgano profesional competente, en consecuencia de infracción ético profesional, por el plazo de 8 (ocho) años, salvo si el acto hubiera sido anulado o suspendido por el Poder Judicial.

62 o) Los que sean demitidos del servicio público en consecuencia de proceso administrativo o judicial, por el plazo de 8 (ocho) años, contados desde la decisión, salvo si el acto hubiera sido suspendido o anulado por el Poder Judicial.

63 q) Los magistrados y los miembros del Ministerio Público que sean jubilados compulsoriamente por decisión sancionatoria, que hayan perdido el cargo por sentencia o que hayan pedido exoneración o jubilación voluntaria en la pendencia de proceso administrativo disciplinario, por el plazo de 8 (ocho) años. 
Pues bien, las inelegibilidades resultantes de condenaciones en procesos electorales (apartados "d"64, “j”65, "n”66 y "p"67), y procesos de naturaleza civil (apartados "h"68, "l"69) no se muestran compatibles con la garantía convencional prevista en la parte final del art. 23.2. El óbice se revela intransponible. La referencia constante en el dispositivo constitucional concerniente a la "vida anterior del candidato" y a la "normalidad y legitimidad de las elecciones" (art. 14, párr. $9^{\circ}$ da Constitución) no es suficiente para otorgar validez a las hipótesis de inelegibilidad que imponen otras restricciones distintas de aquellas definidas en el art. 23.2. El dispositivo convencional exceptúa tan solamente las hipótesis en las que ocurre sanción decurrente de sentencia en proceso penal. Nada más.

Por último, en cuanto a las hipótesis decurrentes de condenaciones criminales (apartado "e"70), los efectos de la inelegibilidad solo pueden advenir de decisión en la que ya haya cosa juzgada.

64 d) Los que tengan contra su persona representación juzgada procedente por la Justicia Electoral, en decisión transitada en juzgado o proferida por órgano colegiado, en proceso de investigación de abuso del poder económico o político, para la elección en la cual concurren o hayan sido diplomados, así como para las que se realicen en los 8 (ocho) años siguientes.

65 j) Los que sean condenados, en decisión transitada en juzgado o proferida por órgano colegiado de la Justicia Electoral, por corrupción electoral, por captación ilícita de sufragio, por donación, captación o gastos ilícitos de recursos de campaña o por conducta vedada a los agentes públicos en campañas electorales que impliquen casación del registro o del diploma, por el plazo de 8 (ocho) años a contar de la elección.

66 n) Los que sean condenados, en decisión transitada en juzgado o proferida por órgano colegiado, en razón de haber disuelto o simulado disolver vínculo conyugal o de unión estable para evitar caracterización de inelegibilidad, por el plazo de 8 (ocho) años después de la decisión que reconoce el fraude.

67 p) La persona física y los dirigentes de personas jurídicas responsables por donaciones electorales consideradas ilegales por decisión transitada en juzgado o proferida por órgano colegiado de la Justicia Electoral, por el plazo de 8 (ocho) años después de la decisión, observando el procedimiento previsto en el art. 22.

68 h) Los titulares de cargo en la administración pública directa, indirecta o fundacional, que se beneficien a sí mismos o a terceros, por el abuso del poder económico o político, que sean condenados en decisión transitada en juzgado o proferida por órgano judicial colegiado, para la elección en la cual concurren o hayan sido diplomados, así como para las que se realicen en los 8 (ocho) años siguientes.

69 1) Los que sean condenados a la suspensión de los derechos políticos, en decisión transitada en juzgado o proferida por órgano judicial colegiado, por acto doloso de improbidad administrativa que importe lesión al patrimonio público y enriquecimiento ilícito, desde la condenación o el tránsito en juzgado hasta el transcurso del plazo de 8 (ocho) años después del cumplimiento de la pena.

70 e) Los que sean condenados, en decisión transitada en juzgado o proferida por órgano judicial colegiado, desde la condenación hasta el transcurso del plazo de 8 (ocho) años después del cumplimiento de la pena, por los crímenes. 
Revistiéndose la inelegibilidad de innegable naturaleza sancionatoria, cuando la Corte condiciona que las restricciones a los derechos políticos solo pueden resultar de sentencia en proceso penal, acaba por extender a la interpretación del régimen de protección el conjunto de precedentes de la Corte en lo relativo a las garantías procesales penales igualmente previstas en la Convención.

Esta cuestión ya fue definida por la Corte ${ }^{71}$ en los siguientes términos:

Las decisiones que emiten los órganos internos en materia electoral pueden afectar el goce de los derechos políticos. Por lo tanto, en dicho ámbito también se deben observar las garantías mínimas consagradas en el artículo 8.1 de la Convención, en cuanto sean aplicables al procedimiento respectivo.

De esta forma, la innovación llevada a cabo por la Ley de la Ficha Limpia (LC No 135/2010), que pasó a reconocer que los efectos serían consecuencia de "decisión transitada en juzgado o proferida por órgano judicial colegiado", viola frontalmente el principio de la presunción de inocencia (por fuerza de la vinculación determinada por el art. 23.2 de la Convención).

El principio de la presunción de inocencia es considerado como una regla de tratamiento, porque orienta que el acusado sea tratado como inocente hasta que haya una sentencia condenatoria transitada en juzgado. Eso impone diversas limitaciones a la forma de actuación del Estado para con el individuo denunciado $^{72}$. En la Convención Americana de Derechos Humanos, en su ámbito de derechos y garantías, se encuentra protegido el principio de la presunción de inocencia. El artículo 8.2 de la Convención dispone que: "toda persona acusada de un delito tiene derecho a que se presuma su inocencia mientras no se compruebe legalmente su culpa" ${ }^{73}$

Se extrae de ese estado de inocencia, reconocido por la Corte Interamericana (y por los tribunales domésticos), de que la única "mitigación” al principio de la presunción de inocencia derivaría de las hipótesis de prisión preventiva, pues allí se trata de protección del proceso, no de anticipación de cualquier efecto condenatorio, ya que cualquier anticipación importa en violación a la garantía del art. 8.2 del Texto Convencional. Por esta razón, la alteración legislativa que anticipa los efectos de la condenación criminal para fines de inelegibilidad

71 Corte IDH. Caso Yatama vs. Nicaragua. Sentencia de 23 de junio de 2005, cit. nota 13, párr. 150.

72 Camargo (2005), p. 57.

73 Convención Americana sobre Derechos Humanos (1969). 
se revela totalmente incompatible con la Convención Americana de Derechos Humanos.

\section{CONSIDERACiONES FINALES}

Desde la edición de la Ley de la Ficha Limpia (LC No 135/2010) se experimenta un proceso de exacerbación del papel a ser asumido por la Justicia Electoral como instancia de control de la legitimidad de los pleitos electorales. De instancia arbitral de contención de los excesos, la Justicia Electoral asume un papel de instancia reformadora de la política (y de los vicios por sí detectados). $\mathrm{Al}$ actuar de esta forma, con el propósito de velar por la legitimidad del pleito, la pretensión de depuración moral de los candidatos a ser controlada por el Poder Judicial (en los procedimientos de impugnación del registro de candidatura) acaba por minar, en última instancia, la propia legitimidad democrática de los sistemas de representación política.

Lo que se pretendió en este trabajo fue confrontar las hipótesis de inelegibilidad infraconstitucional (definidas en el art. $1^{\circ}$ de la LC No 64/90) con la garantía convencional definida en el art. 23.1.b y art. 23.2 de la Convención Americana. Para ello, se buscó confrontar el derecho doméstico con los estándares interpretativos emanados de la Corte Interamericana de Derechos Humanos, a partir de los cuales se puede identificar el contenido y el alcance de la garantía asegurada en la Convención.

La Corte Interamericana de Derechos Humanos posee tres precedentes bastante emblemáticos en relación al alcance de los derechos políticos pasivos y su ámbito de protección ante el Estado. El primero (Caso Yatama vs. Nicaragua ${ }^{74}$ ) en el que se discutió si las restricciones en la Ley Electoral introducida algunos meses antes de las elecciones generales de 2000 no importaron en restricción arbitraria en el derecho de participación política de las comunidades indígenas y tradicionales en el proceso electoral; el segundo (Caso Castañeda Gutman vs. Estados Unidos Mexicanos ${ }^{75}$ ) en el que se discutió la posibilidad de asegurar la candidatura independiente a la Presidencia como consecuencia directa de la garantía convencional prevista en el art. 23.1.b; y el tercero (Caso López Mendoza vs. Venezuela76), en

\footnotetext{
74 Corte IDH. Caso Yatama vs. Nicaragua. Sentencia de 23 de junio de 2005, cit. nota 13.

75 Corte IDH. Caso Castañeda Gutman vs. Estados Unidos Mexicanos. Sentencia de 6 de agosto de 2008, cit. nota 14 .

76 Corte IDH. Caso López Mendoza vs. Venezuela. Sentencia de 11 de setiembre de 2011, cit. nota 10.
} 
el que se discutió específicamente la aplicación de sanciones de inhabilitación en procesos administrativos (cómputo de sanción disciplinaria y regularidad en la ejecución presupuestaria), afirmando que esta hipótesis de suspensión de derechos políticos no estaría autorizada por el art. 23.2 de la Convención.

De estos precedentes, específicamente en relación a esas garantías convencionales, pueden ser identificados los siguientes estándares interpretativos:

(i) los derechos políticos son esenciales para la democracia e imponen una serie de exigencias de protección, teniendo en cuenta el deber de asegurar amplia oportunidad a los ciudadanos de participar efectivamente en la formación de la voluntad política del Estado;

(ii) en el ejercicio del deber de reglamentación de los sistemas electorales, el Estado puede fijar condiciones no previstas en el art. 23.2, a fin de posibilitar el ejercicio concreto del derecho de votar y ser votado (en el sentido de ejercicio de condiciones de habilitación); sin embargo, esta actividad no es libre y se sujeta al control de prohibición de exceso del principio de la proporcionalidad;

(iii) el derecho de ser elegido (23.1.b) es derecho público subjetivo y solo puede ser restringido en estricta observancia a las causas definidas en el art. 23.2, y

(iv) tratándose de suspensión de derechos políticos ante la aplicación de una sanción, es imprescindible que esta reprensión advenga de juez competente, se revista de definitividad y haya sido proferida en proceso penal.

A pesar de que estos precedentes no emanaron de procesos contra el Brasil, los mismos gozan de eficacia erga omnes. En otras palabras, se espera que los demás Estados signatarios puedan incorporar estos estándares como forma de refuerzo recíproco del conjunto de garantías convencionales en el continente regional. Esta eficacia expansiva es tratada por la Corte como res interpretata y ha sido utilizada por las instancias de supervisión supranacional para mensurar el grado de compatibilidad del orden interno a las obligaciones convencionales.

En consecuencia del art. $25 \mathrm{c} / \mathrm{c}$ art. $2^{\circ}$ de la Convención, la Corte reconoce que todos los magistrados nacionales poseen un poder-deber de realizar la confrontación de la legislación nacional en relación a las obligaciones internacionales asumidas por el país. Esta facultad impone a los togados un deber de doble verificación de compatibilidad vertical (control de constitucionalidad y control de convencionalidad). Y es justamente frente a este poder-deber que los magistrados, a despecho de la existencia de decisión vinculante emanada de la Suprema Corte, deben negar vigencia a las reglas infraconstitucionales de las inelegibilidades que sean consideradas incompatibles con la obligación conferida a los ciudadanos en los términos del art. 23.2. 
Para fines de análisis en este trabajo, las hipótesis de inelegibilidad definidas en el art. $1^{\circ}$ de la LC No 64/90 fueron reunidas en cinco grupos distintos.

El primer grupo reúne las situaciones en las que los ciudadanos no ostentan las condiciones exigidas para gozar de los derechos políticos pasivos (apartado "a”) y el último grupo, aquellos que deben desincompatibilizarse en determinado período antes del pleito (incs. II a VII). La reglamentación de estos requisitos resulta de la libertad de conformación de los Estados para emprender la elección de los modelos electorales que serán adoptados. En análisis preliminar, se puede notar que no hay violación evidente en relación a las garantías convencionales. Sin embargo, este análisis podría ser más profundizado si fuese emprendido un análisis de proporcionalidad en los términos fijados en el Caso Castañeda Gutman vs. Estados Unidos Mexicanos, en especial en relación a las hipótesis de inelegibilidad derivada de no desincompatibilización de la función pública ejercida.

Por otro lado, todas las inelegibilidades conminadas en los apartados "b" a "q" no podrían ser integralmente aplicadas de la forma en que están definidas en la legislación brasileña.

El segundo grupo (agentes políticos impugnados y/o que hayan renunciado) y el cuarto grupo (agentes que sufrieron condenaciones administrativas y/o disciplinarias) se revelan flagrantemente inconvencionales porque proyectan las graves restricciones a los derechos políticos pasivos sin que haya un pronunciamiento del órgano judicial competente. De esta forma, una de las hipótesis que resultó en el mayor número de alejamientos en el último pleito general de 2012 (inelegibilidad resultante de rechazo de cuentas, apartado "g") se revela del todo incompatible con la Convención Americana de Derechos Humanos.

El tercer grupo reúne hipótesis en las que las inelegibilidades son consecuencia de sentencias judiciales. Sin embargo, de este grupo las únicas hipótesis que podrían pasar por el filtro de convencionalidad hacen referencia a las inelegibilidades resultantes de decisión criminal. Esto es así porque no basta que las decisiones hayan sido proferidas en procesos judiciales, sino que esos procesos deben tener índole criminal (proceso penal), de lo contrario igualmente esas condenaciones no podrían tener el don de suspender el goce de los derechos políticos pasivos.

Por último, aún en relación a las decisiones proferidas en procesos penales, se supone que sea flagrantemente inconvencional cualquier anticipación de los efectos de la condenación criminal (o sea, anticipación de la inelegibilidad para momento anterior al tránsito en juzgado de la decisión), pues de lo 
contrario se estaría delante de flagrante ofensa al principio de la presunción de inocencia, fundamento de las garantías penales grabado en el art. $8.2 \mathrm{del}$ texto convencional.

Lo que se observa es que en un análisis perentorio la casi totalidad del régimen de las inelegibilidades legales no resiste al control de convencionalidad. Afirmar eso permite no solamente dirigir una crítica contundente al moralismo que el movimiento del "moralismo electoral" 77 , provocó en el ámbito del Poder Judicial, sino que significa, al mismo tiempo, proporcionar fundamentos técnicos para que los jueces electorales puedan dejar de aplicar las reglas flagrantemente inconvencionales y, si fuese el caso, autoriza a que los perjudicados puedan postular el reconocimiento de la violación al derecho de sufragio pasivo ante las instancias de control supranacional.

En última instancia, se trata de afirmar un nuevo frente de batalla contra el papel asumido por el Poder Judicial como alter-ego de la sociedad. A fin de cuentas, se confía en que el aura de incorruptibilidad conferida a las cortes (en detrimento de las demás esferas de poder), acabe por intensificar el proceso de vaciamiento y de demonización de la política y del político. Al fin y al cabo, es la propia democracia la que está bajo ataque y necesita ser rehabilitada.

\section{BiBLIOGRAFÍA CITADA}

Agra, Walber de Mora (2012): "Inconstitucionalidades da incidência da Lei Complementar No 135/2010", en Temas polêmicos de direito eleitoral (Belo Horizonte, Editora Fórum), pp. 11-32.

Camargo, Monica Ovinski de (2005): Princípio da presunção de inocência no Brasil: O Conflito Entre Punir e Libertar (Río de Janeiro, Editora Lumen Juris).

CÂndIDo, Joel José (2012): Direito eleitoral brasileiro (São Paulo, Edipro). Cô̂LHo, Marcus V.F. (2012): Direito Eleitoral e processo eleitoral (Río de Janeiro, Renovar).

77 “(...) un fenómeno peligroso que ha invadido la ciudadela de la jurisprudencia electoral. El moralismo electoral transforma todos los debates jurídicos electorales en debates morales y -lo que es mucho peorsiempre con el compromiso de impedir en todo lo posible que los políticos sean... políticos. En esa lógica hay siempre un sentimiento implícito: entró en la política, es bandido. Y con el anhelo de higienizar la política, se desea acabar con los políticos, lo que no es nada más que sellar el fin de la propia democracia. (...) Es la justicia por la propia mano togada, armada del derecho hallado en la calle". Costa (2013), p. 16. 
Costa, Adriano Soares (2013): Instituiçôes de Direito Eleitoral (São Paulo, Editora Fórum).

Dalla Via, Alberto Ricardo (2011): "Los derechos políticos en el Sistema Interamericano de Derechos Humanos" en Revista Justicia Electoral (Vol. 1, No 8), pp. 15-79.

Ferrer Mac-Gregor, Eduardo (2013): "Eficacia de la sentencia interamericana y la cosa juzgada internacional: vinculación directa hacia las partes (res judicata) e indirecta hacia los Estados Parte de la Convención Americana (res interpretata) (sobre el descumprimiento del Caso Gelman vs. Uruguay)" en Estudios Constitucionales (Año 11, No 2), pp. 641-694.

Gomes, José Jairo (2013): Direito eleitoral (São Paulo, Editora Atlas).

López Zilıo, Rodrigo (2012): Direito eleitoral: noçôes preliminares; elegibilidade e inelegibilidades; açôes eleitorais; processo eleitoral (Porto Alegre, Verbo Jurídico).

Londoño Lázaro, María Carmelina (2010): "El principio de legalidad y el control de convencionalidad de las leyes: confluencias y perspectivas en el pensamiento de la Corte Interamericana de Derechos Humanos", en Boletín Mexicano de Derecho Comparado (Año LXIII, No 128), pp. 761-814. Disponible en: [http://dialnet.unirioja.es/servlet/articulo?codigo=3212723].

Lupi, André L. P. B.; Bastos JR, L. M. P. (2008): “A interpretação da norma internacional em conformidade com seu contexto: uma proposta para aplicação do direito internacional pelos tribunais brasileiros" en XVII Congresso Nacional do CONPEDI (Anales) (Florianópolis, Fundação José Boiteux), pp. 2490-2513.

Nogueira, Humberto (2011a): "Informe pericial Caso López Mendoza vs. Venezuela de Dr. Humberto Nogueira Alcalá”, en Estudios constitucionales (Año 9, n. 1), pp. 339-362.

Nogueira Alcalá, Humberto (2011b): "El uso del postulado de proporcionalidad en la jurisprudencia de la Corte Interamericana sobre libertad de expresión”, en Estudios Constitucionales (Año 9, No 1), pp. 119-156.

Ramos, André de Carvalho (2005): Teoria geral dos direitos humanos na ordem internacional (Río de Janeiro, Editora Renovar).

Rey CANTOR, Ernesto (2009): "Jurisdicción constitucional y control de convencionalidad de las leyes", en X Congreso Iberoamericano de Derecho Constitucional (anales) Lima, Perú, 16-19 set. 2009. 


\section{NORMAS JURÍDICAS CITADAS}

\section{Normas Interamericanas}

Convención Americana sobre Derechos Humanos de 27 de noviembre de 1969.

\section{Normas Nacionales}

\section{Brasil}

LEY No 5.250/67, que dispone sobre la libertad de manifestación del pensamiento y de información. Diario Oficial de la Unión de 10 de febrero de 1967.

Decreto Ley No 972/69, que dispone sobre el ejercicio de la profesión de periodista. Diario Oficial de la Unión de 21 de octubre de 1969.

LEY No 6.683/79, sobre amnistía y otras providencias. Diario Oficial de la Unión de 28 de agosto de 1979.

Ley Complementaria No 64/90, que establece, de acuerdo con el artículo 14, $\$ 9^{\circ}$ de la Constitución Federal, supuestos de inelegibilidad, plazos de cese, y determina otras providencias. Diario Oficial de la Unión de 21 de mayo de 1990.

Decreto No 678/92, que promulga la Convención Americana sobre Derechos Humanos (Pacto de San José de Costa Rica), de 27 de noviembre de 1969. Diario Oficial de la Unión de 09 de noviembre de 1992.

Ley Complementaria No 135/10, que altera la Ley Complementaria No 64, de 18 de mayo de 1990, que establece, de acuerdo con el $\$ 9^{\circ}$ del artículo 14 de la Constitución Federal, casos de inelegibilidad, plazos de cese y determina otras providencias, para incluir supuestos de inelegibilidad que buscan proteger la probidad administrativa y la moralidad en el ejercicio del mandato. Diario Oficial de la Unión de 7 de junio de 2010.

\section{Nicaragua}

LeY No 28, que establece el Estatuto de la autonomía de las regiones de la costa atlántica de Nicaragua. "La Gaceta" (Diario Oficial) No 238 de 30 de octubre de 1987.

Ley No 331, que establece la Ley Electoral. "La Gaceta" (Diario Oficial) No 16 de 24 de enero del 2000. 


\section{JURISPRUDENCIA CITADA}

\section{a) Supremo Tribunal Federal}

BRASIL (2009): Arguição de Descumprimento de Preceito Fundamental n. 130, juzgada el 30.4.2009.

BRASIL (2009): Recurso Extraordinario n. 511.961, juzgado el 17.6.2009.

BRASIL (2010): Arguição de Descumprimento de Preceito Fundamental n. 153, juzgada el 29.4.2010.

BRASIl (2011): Acción Directa de Inconstitucionalidad n. 4578, juzgada el 9.11.2011.

\section{b) Corte Interamericana de Derechos Humanos}

Corte IDH. Caso Almonacid Arrellano y otros vs. Chile (2006). Excepciones Preliminares, Fondo, Reparaciones y Costas. Sentencia de 26 de septiembre de 2006. Serie C No 154

Corte IDH. Caso Barrios Altos vs. Perú. Fondo (2001). Sentencia de 14 de marzo de 2001. Serie C No 75.

Corte IDH. Caso Castañeda Gútman vs. Estados Unidos Mexicanos (2008). Excepciones Preliminares, Fondo, Reparaciones y Costas. Sentencia de 6 de agosto de 2008. Serie C No 184.

Corte IDH. Caso del Tribunal Constitucional vs. Perú (2001). Fondo, Reparaciones y Costas. Sentencia de 31 de enero de 2001. Serie C No 71.

Corte IDH. Caso Gomes Lund y Otros (Guerrilha do Araguaia) vs. Brasil (2010). Excepciones Preliminares, Fondo, Reparaciones y Costas. Sentencia de 24 de noviembre de 2010. Serie C No 219.

Corte IDH. Caso Ivcher Bronstein vs. Perú (2001). Fondo, Reparaciones y Costas. Sentencia de 6 de febrero de 2001. Serie C No 74.

Corte IDH. Caso La Cantuta vs. Perú (2006). Fondo, Reparaciones y Costas. Sentencia de 29 de noviembre de 2006. Serie C No 162.

Corte IDH. Caso López Mendonza vs. Venezuela (2011). Fondo, Reparaciones y Costas. Sentencia de 11 de septiembre de 2011. Serie C No 233.

Corte IDH. Caso Yatama vs. Nicaragua (2005). Excepciones Preliminares, Fondo, Reparaciones y Costas. Sentencia de 23 de junio de 2005. Serie C No 127. 
Corte IDH. La Expresión “Leyes” en el artículo 30 de la Convención Americana sobre Derechos Humanos. Opinión Consultiva OC-6/86 del 9 de mayo de 1986. Serie A No 6.

Corte IDH. Voto Concurrente del Juez Eduardo Vio Grossi en el Caso López Mendonza vs. Venezuela (2011). Fondo, Reparaciones y Costas. Sentencia de 11 de septiembre de 2011. Serie C No 233. 